\title{
Effects of air pollution on acute exacerbation of chronic obstructive pulmonary disease: a descriptive retrospective study (pol-AECOPD)
}

This article was published in the following Dove Press journal: International Journal of Chronic Obstructive Pulmonary Disease

\section{Jairo A Morantes-Caballero Hugo Alberto Fajardo Rodriguez (D)}

Department of Internal Medicine, School of Medicine, Universidad Nacional De Colombia, Hospital Universitario Nacional De Colombia, Bogotá, Colombia
Correspondence: Jairo A MorantesCaballero

Facultad de Medicina, Edificio 47I, Departamento de Medicina Interna, oficina 510. Universidad Nacional Colombia, Sede Bogotá, Carrera 30 No. 45-03, Bogotá, Colombia

Tel +57 I 3165000 ext I50I I-I50I2

Email jamorantesc@unal.edu.co
Purpose: Acute exacerbation of COPD (AECOPD) is among the most frequent causes for hospital admission, causing morbidity and mortality. Infection is the most frequent cause, and studies on pollution have shown higher hospital admission and mortality with inconsistent results. The objective was to identify if there is a change in levels of particulate matter (PM) during the days leading up to the symptom onset.

Patients and methods: A retrospective study was carried out on medical records of patients with AECOPD from a University Hospital. PM values of the consultation day, onset symptoms, and up to three previous days were recorded. Moreover, clinical presentation, laboratory findings, treatments, and hospital outcomes were recorded.

Results: A total of 250 medical records were included, mean age of 77 years, hospital stay mean of 6.7 days, $26.8 \%$ with no previous exposure was identified, coexistence with asthma was $5 \%$, Obstructive Sleep Apnea Syndrome 15\%, Pulmonary Hypertension 34\%, antibiotic use 62\%, ICU admission of $14 \%$ with non-invasive mechanical ventilation of $68 \%$, and in-patient mortality of $2.4 \%$. PM 2.5 of $48 \mathrm{hrs}$ before onset symptoms median was $20.1 \mu \mathrm{g} / \mathrm{m}^{3}$ versus 15 and 16.5 for the day of symptoms and 3 days prior to onset symptoms $(p<0.001)$. PM 10 of $46.65 \mu \mathrm{g} /$ $\mathrm{m}^{3}$, versus 39 and 35.6, respectively $(p<0.001)$. Expectoration OR 4.74; Purulence OR 6.58; Pleuritic pain OR 3.62; Antibiotic use OR 2.87, and corticoids use OR 2.62, all with $p<0.05$.

Conclusions: Patients with AECOPD have a higher median of particulate matter $48 \mathrm{hrs}$ prior to symptomatic onset, as well as greater use of antibiotics and corticosteroids.

Keywords: pulmonary disease, chronic obstructive, particulate matter, air pollutants

\section{Introduction}

Chronic obstructive pulmonary disease (COPD) represents one of the main causes of morbidity and mortality worldwide. According to the latest report of the World Health Organization, ${ }^{1}$ it is estimated that in 2008 in the United States 15 million people suffered from it, as well as 210 million people worldwide, with an associated mortality of 3 million people. ${ }^{2}$ COPD generates not only respiratory complications but also cardiovascular ones, ${ }^{3}$ and even osteoporosis. ${ }^{4}$ The deterioration in symptoms beyond the daily variation that leads to the use of additional therapy is known as Acute Exacerbation of COPD (AECOPD), being the most frequent cause of medical hospital admission in the United Kingdom with almost $15.9 \%$ of the medical hospitalizations. ${ }^{5-7}$ In $22 \%$ of the patients with very severe COPD, exacerbation recurs, on average, 50 days after the first episode ${ }^{5}$ and generating a $25 \%$ deterioration of lung function, ${ }^{8}$ thus increasing mortality, making it five times 
higher in the tenth episode when compared to the first, ${ }^{6}$ and up to $50 \%$ when in the Intensive Care Unit. ${ }^{9}$ The cause of AECOPD can be infectious $(40-60 \%)^{6}$ and noninfectious (smoking, pulmonary thromboembolism, and air pollution or exposure to particulate matter, PM). ${ }^{10}$

Regarding exposure to PM, people exposed to environmental pollution have a greater proportion of lung dysfunction with an excess risk of $64 \%$, which when combined with smoking increases to $129 \% .{ }^{11}$ Likewise, it is related to higher hospital admission, ${ }^{12}$ deterioration of FEV1, ${ }^{13}$ and mortality. ${ }^{14}$ However, assuming that environmental exposure can exacerbate COPD, the objective of this study was to examine whether the levels of PM below 2.5 (PM2.5) and 10 microns (PM10) in the days before the symptomatic onset in adult patients with AECOPD show any change, and if that is associated with clinical presentation or outcome of an Anthonisen classification, use of antibiotic, hospitalization days, admission to ICU, and mortality.

\section{Materials and methods}

The protocol was approved by the institutional review board of Universidad Nacional de Colombia Number 004-033-17. Patient consent to review their medical review records was not required by the board, and thus no identifying information such as name, Identification number, and Medical number were used, and it was conducted in accordance with the principles of the Declaration of Helsinki.

\section{Study design and participants}

A retrospective study was conducted with medical records of adult patients hospitalized at the Hospital Universitario Nacional de Colombia (Bogotá, Colombia), with an admissions diagnosis of AECOPD (ICD 10: J441 to J449) between the months of April 2016 and April 2017 and residents in places with air quality measurement. Exposure higher to the daily average levels recommended by the WHO is of $25 \mu \mathrm{g} / \mathrm{m}^{3}$ and $50 \mu \mathrm{g} / \mathrm{m}^{3}$ for PM2.5 and PM10, respectively. ${ }^{15}$ Computer records of the medical records with the following inclusion criteria were taken: patient over 18 years of age with a spirometric diagnosis of COPD who came in due to respiratory symptoms that suggested acute exacerbation of COPD, from a borough that has air quality measurement. Patients with other diagnoses that explained the clinical profile, missing data referring to diagnosis or treatment, and residents in areas where there is not a meteorological station into a kilometer radius or does not have PM measurements were excluded.

\section{Sampling}

If they met the inclusion criteria, medical histories were selected by non-probabilistic convenience sampling in order of arrival. A sample size of 200 was calculated for mean differences of independent samples in order to detect mean differences between levels of PM2.5 and PM10 of $0.2 \mu \mathrm{g} / \mathrm{m}^{3} / 24 \mathrm{hrs}$, with a standard deviation of $0.5 \mu \mathrm{g} / \mathrm{m}^{3} / 24$ hrs, a statistical power of $80 \%$ and $95 \%$ confidence, calculated using the Epidat software (Version 4.1, Oct 2014, PAHO-WHO). Twenty percent of the estimated losses were added due to missing data, totaling 240 . The record was made in EXCEL and the analysis in EPIDAT.

\section{Bias control}

PM2.5 and PM10 values from the day of consultation, day of symptom onset, and three days prior to it were recorded. To achieve this, during hospital admission, each patient had to register their place of residence, the nearest meteorological station was located, and the average values for $24 \mathrm{hrs}$ of PM2.5 and PM10 were recorded. In addition, variables of clinical presentation were recorded such as increased dyspnea, expectoration and sputum change, pleuritic pain, fever and altered state of consciousness, clinical examinations and, as outcome variables, the use of antibiotics, corticosteroids, admission to the Intensive Care Unit (ICU), days at the ICU, ventilatory support requirement, new indication for oxygen therapy, and in-patient mortality. The bias control was made by selecting those exposed in an automated way using the software. Temperature, precipitation, humidity, and alternative pollutants were registered, but these had rarely been collected, about $10 \%$; therefore, these were excluded from the analysis.

A univariate analysis in proportions with $95 \%$ confidence intervals and central tendency and dispersion measurements considered normal distributions by Shapiro-Wilk test with a 0.05 significance that characterizes the exacerbation of COPD according to person, time, and place variables was performed. A median difference was made using the Kruskal-Wallis statistic with a significance less than 0.05 . Finally, to determine the secondary objectives and control of confounding variables, a multivariate logistic regression analysis was carried out in search of the association between qualitative variables (Anthonisen Group, use of antibiotic and admission to ICU), and PM10 and 2.5 levels registered at the time of symptom onset, three days prior to the consultation and a cumulative total of four days with control of confounding variables, including variables that show statistical significance defined 
by the Wald statistic with a significance below 0.05 . All graphs and analyses were made using the GraphPad Prism software (GraphPad Prism version 7.00 for Windows, GraphPad Software, La Jolla, California, USA) through license GPS1,030,895-EFOT-DAF4F. The final document was written according to the STROBE initiative ${ }^{16}$

\section{Results}

We reviewed 1549 medical records, finally including 250 (see Figure 1). The demographic characteristics can be seen in Table 1. Twenty-eight percent of the patients did not have previous spirometric diagnosis; coexistence with asthma

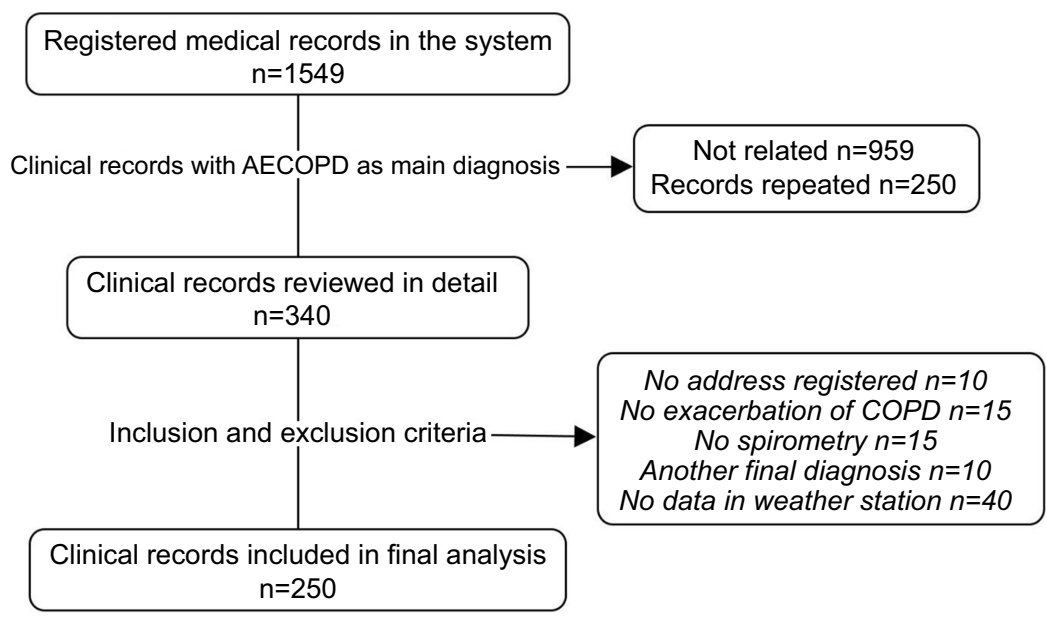

Figure I Selection algorithm of medical records. AECOPD: Acute exacerbations of chronic obstructive cardiopulmonary disease. Flow-chart of clinical records included.

Table I Clinical-demographic characteristics of the patients included in the study

\begin{tabular}{|c|c|c|c|c|}
\hline Characteristic & Frequency (n) & Proportion (\%) & Mean & IC95\% \\
\hline $\begin{array}{l}\text { Age (years) } \\
\text { Symptom duration (days) } \\
\text { Hospitalization duration (days) } \\
\text { Female }\end{array}$ & 147 & . & $\begin{array}{l}77.4 \\
7.8 \\
6.7\end{array}$ & $\begin{array}{l}{[76.1-78.8]} \\
{[7.09-8.62]} \\
{[6.23-7.25]} \\
{[52.8-64.9]}\end{array}$ \\
\hline $\begin{array}{l}\text { GOLD A } \\
\text { B } \\
\text { C } \\
\text { D }\end{array}$ & $\begin{array}{l}17 \\
21 \\
56 \\
90\end{array}$ & $\begin{array}{l}6.8 \\
8.4 \\
22.4 \\
36.0\end{array}$ & & \\
\hline $\begin{array}{l}\text { Asthma } \\
\text { Interstitial disease } \\
\text { PHT } \\
\text { OSA } \\
\text { Atrial fibrillation } \\
\text { Arterial hypertension } \\
\text { Diabetes mellitus } \\
\text { Smoking } \\
\text { No documented exposure }\end{array}$ & $\begin{array}{l}13 \\
13 \\
87 \\
37 \\
37 \\
155 \\
46 \\
120 \\
67\end{array}$ & $\begin{array}{l}5.2 \\
5.2 \\
34.8 \\
14.8 \\
14.8 \\
62.0 \\
18.4 \\
48.0 \\
26.80\end{array}$ & & $\begin{array}{l}{[3.0-8.7]} \\
{[3.0-8.7]} \\
{[10.9-19.8]} \\
{[10.9-19.8]} \\
{[56.0-68.0]} \\
{[14.1-23.7]} \\
{[42.0-54.3]} \\
{[21.7-32.7]}\end{array}$ \\
\hline $\begin{array}{l}\text { Anthonisen I } \\
\text { II } \\
\text { III }\end{array}$ & $\begin{array}{l}103 \\
78 \\
69\end{array}$ & $\begin{array}{l}41.2 \\
31.2 \\
27.6\end{array}$ & & $\begin{array}{l}{[35.4-47.5]} \\
{[25.8-37.3]} \\
{[22.5-33.5]}\end{array}$ \\
\hline
\end{tabular}

Notes: Clinical characteristics table at hospital admission with proportions for categorical, and dispersion measures and central tendency for the continuous ones. Anthonisen criteria which comprise three patient-reported items: increased dyspnea, increased sputum volume, and increased sputum purulence. Type I exacerbation - all three symptoms; Type II exacerbation - two of the three clinical symptoms; Type III exacerbation - one of the three clinical symptoms.

Abbreviations: GOLD, Global Initiative for Chronic Obstructive Lung Disease; PHT, pulmonary hypertension; OSA, Obstructive Sleep Apnea Syndrome. 
occurred in 5\%; one-third of the patients presented pulmonary hypertension (PHT), with an average systolic pulmonary artery pressure (SPAP) of $57 \mathrm{mmHg}$ measured by transthoracic echocardiography and generating pulmonary heart disease in $15 \%$ of them. PHT was more frequent among GOLD D patients (34\%) when compared with GOLD A and B which had $4 \%$ and $3 \%$, respectively ( $p=0.043$ ) (Figure 2 ), as well as higher SPAP-values in GOLD D patients $(p=0.023)$. In $26 \%$, no previous exposure to smoking or combustion of biomass was identified. Regarding the clinical presentation, frequent symptoms were increased dyspnea 95\% $(n=238)$, increased expectoration $89 \%(n=174)$, and increased cough $215(85 \%)$; fever only occurred in $42 \%$ of the cases $(n=105)$. Regarding clinical tests, the mean of $\mathrm{pCO}_{2}$ was $37.5 \mathrm{mmHg}, \mathrm{HCO}_{3}$ of $27.3 \mathrm{mEq} / \mathrm{Lt}$. Likewise, 20.8\% $(\mathrm{n}=52)$ presented anemia according to WHO criteria, ${ }^{17}$ and $7.2 \%(\mathrm{n}=18)$ presented polyglobulia. On the other hand, antibiotic was used in $62 \%$ of the patients, predominantly beta-lactam antibiotics, requiring change in $13.7 \%$ of the cases due to non-responsiveness in $40 \%$ of them $(n=9)$, but indicating therapeutic failure in $5.6 \%$ $(n=9)$ of all patients undergoing antibiotic use. Patients admitted without previous use of home oxygen, $40 \%(n=46)$, were prescribed this therapy after hospital discharge and inpatient mortality was 1.2 per 100 people per year (See Table 2 ).

\section{Environmental pollution}

As high as $11.6 \%$ of the data were not recorded for the different stations. Regarding PM values, the median of PM2.5 recorded for $24 \mathrm{hrs}$ was $16.4 \mu \mathrm{g} / \mathrm{m}^{3}$ with a range of 0.9 to $49.3 \mu \mathrm{g} / \mathrm{m}^{3}$, with $30 \%$ of the values above those established. For PM10, the median was $37.7 \mu \mathrm{g} / \mathrm{m}^{3}$ with a

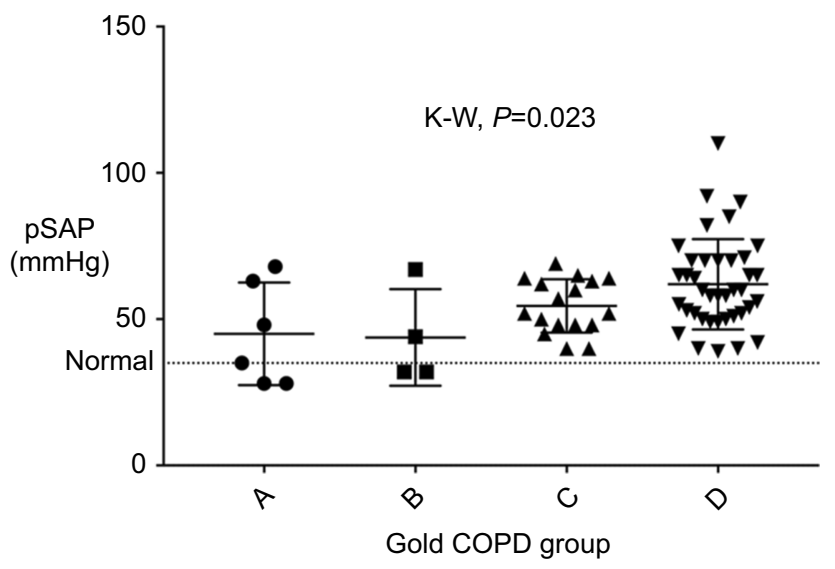

Figure 2 Frequency and distribution of PSAP-values according to COPD severity. The distribution of the value medians for systolic pressure of the pulmonary artery (PSAP) according to the severity of the COPD classified by GOLD is shown; $p$-values are shown for the Kruskal-Wallis statistic (KW). range of 6.7 to $103 \mu \mathrm{g} / \mathrm{m}^{3}$ and records higher than those of WHO for $32.3 \%$ of the cases. Likewise, the median of the daily averages of PM2.5 in the $48 \mathrm{hrs}$ prior to the symptom onset was $20.1 \mu \mathrm{g} / \mathrm{m} 3$, compared with 15 and $16.5 \mu \mathrm{g} / \mathrm{m}^{3}$ for the day of the symptoms and the three previous initial days, differences that were statistically significant $(p<0.001)$. In the case of PM10, the median of these levels on the second day before the symptom onset was $46.65 \mu \mathrm{g} / \mathrm{m}^{3}$, compared with 39 and 35.6 on the third day after symptom onset $(p<0.001)$ (see Figure 3).

Additionally, during the day of symptom onset, patients with Anthonisen I or II presented 1.4 times more PM2.5 values greater than $25 \mu \mathrm{g} / \mathrm{m}^{3}$ (OR 2.45, 95\% CI [1.13-5.31], $p=0.019)$. Likewise, high levels of PM2.5 were associated with increased expectoration, purulence, pleuritic pain, and antibiotic and corticosteroid use (Table 3 ). Regarding values for the day of consultation, no statistically significant associations were found between exposure to high levels of PM2.5 and symptoms, treatment, or outcomes. On the other hand, it was found that patients who were started on corticosteroids or those who were discharged with a new order for an oxygen therapy were associated with Anthonisen I and II (OR 3.33, 95\% CI [1.81-6.30] and OR 2.24; \% [1.20-4.17], respectively).

\section{Discussion}

The role of environmental pollution in the exacerbation of COPD is increasing. In recent years, a growing number of studies have been published with the intention of evaluating the impact of exposure to PM2.5 and PM10 in AECOPD, evidencing deterioration of FEV1 and higher mortality. However, for the increase in hospital admissions, the results have been inconsistent. $^{12,18}$ The main objective of this study was to identify a variation in PM levels prior to symptoms since this aspect has been insufficiently studied. A significant finding was the evidence of change in the $48 \mathrm{hrs}$ prior to the symptom onset, suggesting a possible role in the pathogenesis of AECOPD, but prospective studies are required.

In addition to the effect on the symptom onset, there was also an association with the increase in expectoration, purulence, and even pain referred to as pleuritic, which leads to a higher probability of being classified as Anthonisen I-II and, therefore, an increased use of antibiotics is needed in $70 \%$ of the patients exposed to PM2.5 greater than $25 \mathrm{mcgr} / \mathrm{m}^{3}$ compared to a $60 \%$ of the antibiotic use in unexposed individuals $(p=0.016)$; 
Table 2 Course and clinical outcome of hospitalized patients

\begin{tabular}{|c|c|c|}
\hline Characteristic & Frequency (n) & Proportion (\%) \\
\hline Intensive care unit & 35 & 14.0 \\
\hline Ventilation & 22 & 62.8 \\
\hline - NIMV & 15 & 68.1 \\
\hline Vasoactive & 7 & 31.8 \\
\hline Community-acquired pneumonia & 52 & 20.8 \\
\hline ANTIBIOTIC USE & 160 & 64.0 \\
\hline - Ampicillin/sulbactam & 95 & 59.4 \\
\hline - Piperacillin/tazobactam & 35 & 21.9 \\
\hline - Doxycycline & 17 & 10.6 \\
\hline - Clarithromycin & 4 & 2.5 \\
\hline Combination & 59 & 36.8 \\
\hline - Clarithromycin & 55 & 93.2 \\
\hline Modificated & 22 & 13.7 \\
\hline - Piperacillin/tazobactam & 7 & 31.8 \\
\hline - Meropenem & 2 & 9 \\
\hline \multicolumn{3}{|l|}{ Inhalation therapy } \\
\hline Beta-agonist & $|7|$ & 68.4 \\
\hline Albuterol & 150 & 87.7 \\
\hline - Salmeterol & 12 & 7.0 \\
\hline Anticholinergic & 223 & 89.2 \\
\hline - Ipratropium. B & 203 & 91.0 \\
\hline - Tiotropium & 20 & 8.9 \\
\hline Corticosteroids & $12 \mid$ & 48.4 \\
\hline - Intravenous & 66 & 54.5 \\
\hline - Oral & 102 & 84.2 \\
\hline Home oxygen & 46 & 39.7 \\
\hline Mortality & 6 & 2.4 \\
\hline
\end{tabular}

Notes: Table with proportions of pharmacological and non-pharmacological treatments received by patients during their stay in the Hospital as well as their outcomes. Abbreviation: NIMV, non-invasive mechanical ventilation.
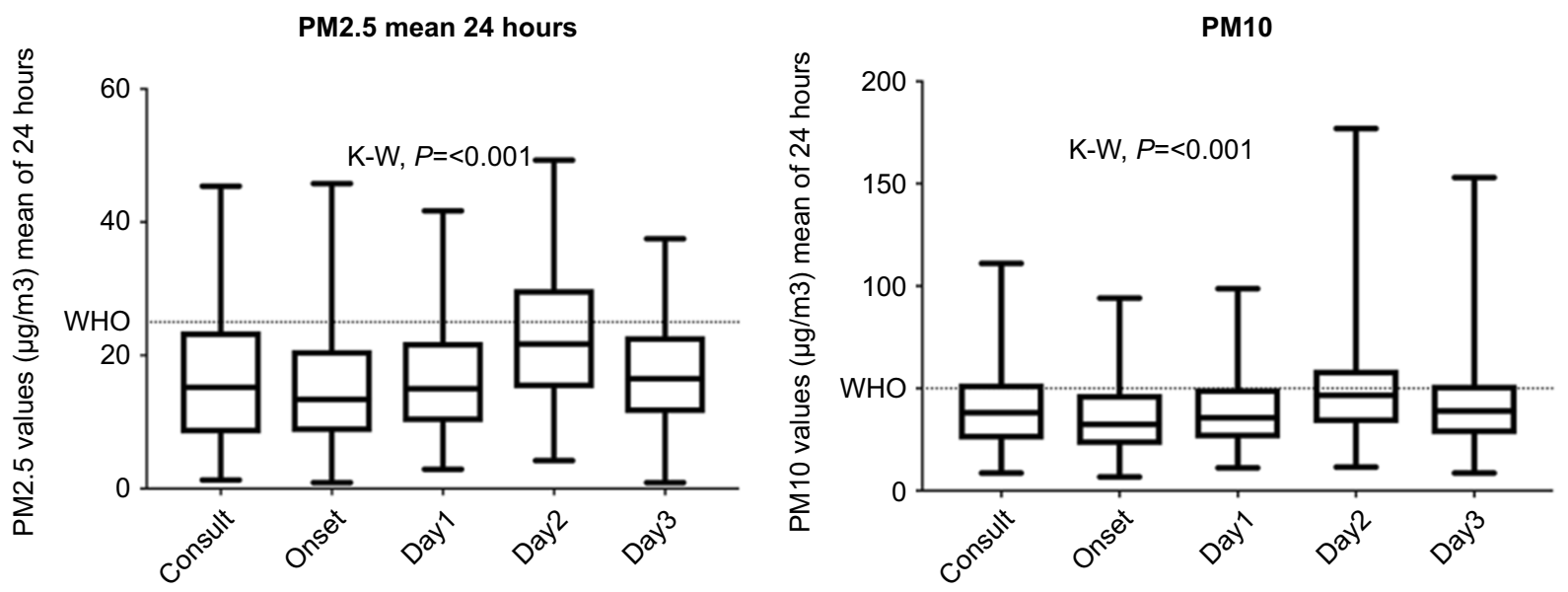

Figure 3 (A, B) PM2.5 and PMI0 values, according to the day of consultation and days before the symptom onset. The medians are represented for mean values of 24 hrs for PM2.5 and PM10, according to the day of consultation, day of symptom onset (DaySx), the day before the symptom onset (Dayl), two days before (Day2), and three days before the symptom onset (Day3). Dotted line: Upper limit recommended by the WHO. Kruskal-Wallis (K-W) statistic for median differences. Significant $p$-value $<0.05$. 


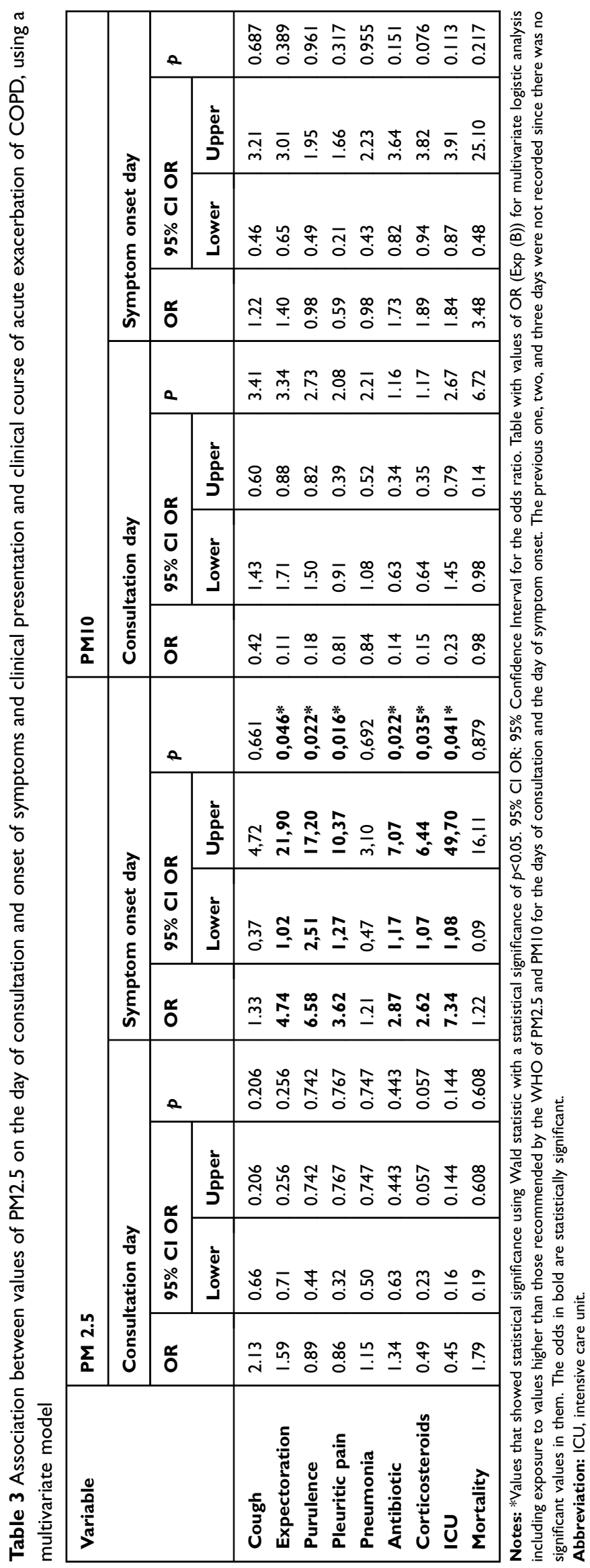


the aforementioned is due to a collinearity effect. It should be noted that, in general, the use of antibiotics was $64 \%$, while the one reported in previous studies was between $74.8 \%$ and $86 \% .{ }^{19}$ Likewise, diagnosing pneumonia in patients with exacerbation of COPD of $20.8 \%$ is of interest, since their coexistence is associated with greater use of health resources, due to a long hospital stay, admission to the ICU and the performance of inpatient procedures. Such association has been described in $36.1 \%$ of the first episodes of exacerbation and in $25.6 \%$ of the subsequent hospitalizations, increasing even the risk of in-patient mortality (adjusted HR 1.20, 95\% CI [1.17-1.24]). ${ }^{20}$ The association between PM, symptomatology, and antibiotic onset could be due to the fact that PM inhibits phagocytosis and increases free radicals with a subsequent lesion of the bronchial epithelium, increased inflammatory response and production of Tumor Necrosis Factor-alpha and Interleukin-1, which perpetuate inflammation affecting mucociliary movement, favoring viral and bacterial infection. ${ }^{21}$ On the other hand, it was found that exposure to values higher than $25 \mathrm{mcgr} / \mathrm{m}^{3}$ of PM2.5, by making it more likely to be classified as Anthonisen I or II, also increases the probability of using corticosteroids as a treatment, since there is an interaction between the three variables.

On the other hand, of the patients hospitalized due to AECOPD, $16 \%(n=35)$ required admission to the Intensive Care Unit, of which approximately $70 \%$ received invasive mechanical ventilation; similar to the findings of those reported in the literature. ${ }^{22}$ The median stay was 4 days, which is less than that reported in previous studies which were of 6 and 8 days. ${ }^{23,24}$ Regarding environmental pollution, patients admitted to the ICU were more likely to have exposure to high levels of PM2.5 compared to those who were not admitted into the ICU; however, in these patients, there was no increased requirement for ventilatory or vasoactive support. The previously reported in-patient mortality due to exacerbation of COPD was of 7.5\% and $11 \%{ }^{22-25}$ in this study, it was $2.4 \%$.

Another finding is the identification of patients with pulmonary tuberculosis in approximately $3.2 \%(n=8)$ of the cases. This association is noteworthy because tuberculosis can cause exacerbation, and it is also a possible etiology of COPD since the prevalence of COPD in patients with pulmonary tuberculosis is higher than that of non-infected patients, being $30.7 \%$ versus $13.9 \%$, respectively. $^{26,27}$ Following that train of thought, the study of tuberculous infection in patients with AECOPD in endemic countries is recommended.

Finally, the weaknesses of the study are those typical of retrospective studies, where memory bias could affect the dates of symptom onset, especially in patients with prolonged symptoms. Likewise, the data record can omit important details. On the other hand, $11 \%$ of the PM values were not recorded in the different stations. However, estimating this loss, the sample size was increased by $20 \%$. Influenza epidemics were not taken into account in the statistical analysis. No microbiological study was performed for any case in order to discern between infectious or non-infectious exacerbation. Medical criteria were taken into account, so the findings described here only serve to generate hypotheses and do not express a real cause-effect relationship. On the other hand, the strength of the study is the guidance toward a more clinical scope, the impact of environmental pollution, beyond hospital admissions or mortality, being able to roughly explain a possible clinical effect and, especially, an association with greater use of antibiotics. Furthermore, it shows a possible change in the levels of external contaminants prior to the symptomatic profile, a finding not previously described in the literature.

\section{Conclusions}

According to the findings of this study, patients hospitalized for AECOPD have increased levels of PM2.5 and PM10 in the $48 \mathrm{hrs}$ prior to the symptomatic onset. In addition, elevated levels of PM during the day of symptom onset are associated with a higher finding of increased sputum volume, purulence, pleuritic pain, and use of antibiotics and corticosteroids. Taking into account the limitations of this study, prospective studies should be conducted to evaluate the associations presented here.

\section{Responsibility for data}

For efficacy data: Dr Jairo Morantes-Caballero has personally reviewed the efficacy data, understands the statistical methods employed for efficacy analysis, and confirms an understanding of this analysis, that the methods are clearly described, and that they are a fair way to report the results. For safety data: Dr Jairo Morantes-Caballero has personally reviewed the safety data. He understands the statistical methods employed for safety analysis and confirms that he understands this analysis, that the methods are clearly described, and that they are a fair way to report the results. For 
study design: Dr Jairo Morantes-Caballero confirms that the study objectives and procedures are honestly disclosed. Moreover, he has reviewed study execution data and confirms that procedures were followed to an extent that convinces all authors, that the results are valid and generalizable to a population similar to that enrolled in this study.

\section{Acknowledgments}

The authors thank the Hospital Universitario Nacional de Colombia and its directors for allowing us to carry out the study and access the patients' medical records, to Dr Alfredo Saavedra, pulmonologist, for his contribution in the discussion of this study, and to my wife Angie Ortiz. All of this work's costs were covered by the authors.

\section{Author contributions}

All authors contributed to data analysis, drafting or revising the article, gave final approval of the version to be published, and agree to be accountable for all aspects of the work.

\section{Disclosure}

The authors report no conflicts of interest in this work.

\section{References}

1. World Health Organization, Organization WH. World health Statistics 2008. World Heal Organ [Internet]; 2008:112. Available from: http:// www.who.int/whosis/whostat/EN_WHS08_TOCintro.pdf. Accessed 30 January, 2016.

2. Bousquet J, Kiley J, Bateman ED, et al. Prioritised research agenda for prevention and control of chronic respiratory diseases. Eur Respir J. 2010;36(5):995-1001. doi:10.1183/09031936.00012610

3. Mannucci PM, Harari S, Martinelli I, Franchini M. Effects on health of air pollution: a narrative review. Intern Emerg Med. 2015;1-6. doi:10.1007/s11739-015-1276-7

4. Chang K-H, Chang M-Y, Muo C-H, et al. Exposure to air pollution increases the risk of osteoporosis: a nationwide longitudinal study. Medicine. 2015;94(17):e733. doi:10.1097/MD.0000000000000733

5. Wedzicha JA, Seemungal TA. COPD exacerbations: defining their cause and prevention. Lancet. 2007;370(9589):786-796. doi:10.1016/ S0140-6736(07)61382-8

6. Wedzicha JA, Singh R, Mackay AJ. Acute COPD exacerbations. Clin Chest Med. 2014;35(1):157-163. doi:10.1016/j.ccm.2013.11.001

7. Voelkel NF, Tuder R. COPD * exacerbation. Chest. 2000;117 (5):376S-379S. doi:10.1378/chest.117.5_suppl_2.376S

8. Donaldson GC, Seemungal TAR, Bhowmik A, Wedzicha JA. Relationship between exacerbation frequency and lung function decline in chronic obstructive pulmonary disease. Thorax. 2002;57 (10):847-852. doi:10.1136/thorax.57.10.847

9. Aburto M, Esteban C, Moraza FJ, Aguirre U, Egurrola M, Capelastegui A. COPD exacerbation: mortality prognosis factors in a respiratory care unit. Arch Bronconeumol. 2011;47(2):79-84. doi:10.1016/j.arbres.2010.10.012
10. Tillie-Leblond I, Marquette C-H, Perez T, et al. Pulmonary embolism in patients with unexplained exacerbation of chronic obstructive pulmonary disease: prevalence and risk factors. Ann Intern Med. 2006;144(6):390-396. doi:10.7326/0003-4819-144-6-20060321000005

11. Martínez-López E, Díaz-Valencia PA. Respirar aire contaminado es tan nocivo como fumar cigarrillo. Rev Salud Pública. 2015;17 (3):365-378. doi:10.15446/rsap.v17n3.38428

12. Song Q, Christiani DC, Wang X, Ren J. The global contribution of outdoor air pollution to the incidence, prevalence, mortality and hospital admission for chronic obstructive pulmonary disease: a systematic review and meta-analysis. Int $J$ Environ Res Public Health. 2014;11(11):11822-11832. doi:10.3390/ ijerph111111822

13. Tanaka T, Miyamoto N, Kozu R, Satomi K, Honda S, Senjyu H. Physical function traits of long-term officially acknowledged victims of pollution-related illnesses compared with elderly patients with chronic obstructive pulmonary disease. J Phys Ther Sci. 2014;26 (10):1605-1608. doi:10.1589/jpts.26.1605

14. Beelen R, Raaschou-Nielsen O, Stafoggia M, et al. Effects of longterm exposure to air pollution on natural-cause mortality: an analysis of 22 European cohorts within the multicentre ESCAPE project. Lancet. 2014;383(9919):785-795. doi:10.1016/S0140-6736(13) 62158-3

15. OMS. Guías de calidad del aire de la OMS relativas al material particulado, el ozono, el dióxido de nitrógeno y el dióxido de azufre (Actualización 2005) [Internet]; 2005. Available from: http://apps. who.int/iris/bitstream/10665/69478/1/WHO_SDE_PHE_OEH_06. 02_spa.pdf. Accessed January 30, 2016.

16. von Elm E, Altman DG, Egger M, Pocock SJ, Gøtzsche PC, Vandenbroucke JP. The Strengthening the Reporting of Observational Studies in Epidemiology (STROBE) statement: guidelines for reporting observational studies. J Clin Epidemiol. 2008;61 (4):344-349. doi:10.7326/0003-4819-147-8-200710160-00010

17. Organización Mundial de la Salud. Concentraciones de hemoglobina para diagnosticar la anemia y evaluar su gravedad. VMNIS. 2011;11(1):7.

18. Ko FWS, Hui DSC. Air pollution and chronic obstructive pulmonary disease. Respirology. 2012;17(3):395-401. doi:10.1111/j.14401843.2011.02112.x

19. Lopez-Campos JL, Hartl S, Pozo-Rodriguez F, Roberts CM. Antibiotic prescription for COPD exacerbations admitted to hospital: European COPD audit. PLoS One. 2015;10(4):e0124374. doi:10.1371/journal.pone. 0124374

20. Sogaard M, Madsen M, Lokke A, Hilberg O, Sorensen HT, Thomsen RW. Incidence and outcomes of patients hospitalized with COPD exacerbation with and without pneumonia. Int $J$ Chron Obstruct Pulmon Dis. 2016;11:455-465. doi:10.2147/COPD.S96179

21. Ling SH, van Eeden SF. Particulate matter air pollution exposure: role in the development and exacerbation of chronic obstructive pulmonary disease. Int J Chron Obstruct Pulmon Dis. 2009;4:233243. doi:10.2147/COPD.S5098

22. Moran JL, Green JV, Homan SD, Leeson RJ, Leppard PI. Acute exacerbations of chronic obstructive pulmonary disease and mechanical ventilation: a reevaluation. Crit Care Med. 1998;26(1):71-78. doi:10.1097/00003246-199801000-00019

23. Funk G-C, Bauer P, Burghuber OC, et al. Prevalence and prognosis of COPD in critically ill patients between 1998 and 2008. Eur Respir J. 2013;41(4):792-799. doi:10.1183/09031936.00226411

24. Rello J, Rodríguez A, Torres A, et al. Implicaciones de la EPOC en pacientes ingresados en la unidad de cuidados intensivos por neumonía adquirida en la comunidad. Eur Respir J. 2006;7(3):218224. doi: $10.1157 / 13075996$

25. Yousif M, El Wahsh RA. Predicting in-hospital mortality in acute exacerbation of COPD: is there a golden score? Egypt $J$ Chest Dis Tuberc. 2016;65(3):579-584. doi:10.1016/j.ejcdt.2016.03.003 
26. Garcia-Sanz M-T, Canive-Gomez J-C, Senin-Rial L, et al. One-year and long-term mortality in patients hospitalized for chronic obstructive pulmonary disease. $J$ Thorac Dis. 2017;9(3):636-645. doi: $10.21037 /$ jtd.2017.03.34
27. Suissa S, Dell'Aniello S, Ernst P. Long-term natural history of chronic obstructive pulmonary disease: severe exacerbations and mortality. Thorax. 2012;67(11):957-963. doi:10.1136/thoraxjnl-2011-201518

\section{Publish your work in this journal}

The International Journal of COPD is an international, peer-reviewed journal of therapeutics and pharmacology focusing on concise rapid reporting of clinical studies and reviews in COPD. Special focus is given to the pathophysiological processes underlying the disease, intervention programs, patient focused education, and self management protocols. This journal is indexed on PubMed Central, MedLine and CAS. The manuscript management system is completely online and includes a very quick and fair peer-review system, which is all easy to use. Visit http://www.dovepress.com/testimonials.php to read real quotes from published authors. 